\title{
Improvement of thermal processing during product manufacture at small enterprises
}

\author{
Alexandr Alexandrovich Afanasiev \\ Department of standardization and quality control \\ Belgorod State Technological University named after \\ V.G. Shukhov \\ BSTU named after V.G. Shoukhov \\ Belgorod, Russia \\ alexaf-42@mail.ru
}

\author{
Anatoliy Alexeevich Pogonin \\ Engineering technology Department \\ Belgorod State Technological University named after \\ V.G. Shukhov \\ BSTU named after V.G. Shoukhov \\ Belgorod, Russia \\ alexaf-42@mail.ru
}

\begin{abstract}
The work presents the results of comparative chemical and thermal processing analysis of components at one of the small enterprises of the Central Black Earth Region and one of the plants in France. The modern examination equipment allows carrying out the metallographic studies more accurately, developing the metallographic specimens with a high quality surface under study that was impossible to achieve 10-15 years ago. It makes it possible to improve the quality of components produced by small enterprises and to raise their degree of cooperation with parent enterprises to a higher level.
\end{abstract}

Keywords - thermal processing, alloy microstructure, nanotechnology, electron microscopy, martensitic transformation, austenite decomposition

\section{INTRODUCTION}

The modern scientific and technological progress reached such level that the further development of component production requires the interaction of state-of-the-art technologies and studies of material internal structure at a higher level. The attaining of limiting possibilities in studies of material and alloy microstructures as a result of thermal processing is connected to the high-resolution techniques of the scanned probe microscopy [1, 2]: scanning optical microscopy, scanning electron microscopy, scanning tunneling microscopy and atomic force microscopy when combined with the laser interferometry and phasometry. In view of the forthcoming development of mechanical facilities in Russia and taking into account the State size and raw material sources, the role of small enterprises connected to parent companies can have the dramatic upright changes in their expediency and significance for economic development. The focus should be brought on the modern multiprocessing machine tools and innovations at all stages of the product life cycle [3] including the component thermal processing area.

One of the most important stages of the product life cycle is a production process where data and scientific research information analysis is of continued importance.

\section{EXPERIMENTAL PART}

\section{A. Methods}

The research technique is based on MIRA-3 LM scanning probe electron microscope that allows studying the steel or alloy chemical composition of the metallographic specimen under consideration and getting high-resolution images of the superficial portion. The metallographic specimens are produced with semi-automatic machines, diamond grinding, surface polishing and chemical treatment. In other words, the metallographic study diagram is almost standard, but the process of going through procedures and operations is at a higher technical and technological level. The modern examination equipment allows carrying out the metallographic studies more accurately, developing the metallographic specimens with a high quality surface under study that was impossible to achieve 10-15 years ago.

\section{B. Materials}

The work presents the results of comparative chemical and thermal processing analysis of components at one of the small enterprises of the Central Black Earth Region and one of the plants in France.

To carry out this study, the authors made the following lockout of study and analysis targets:

Sample workpiece 1 - component produced in France.

Sample workpiece 2 - home produced component, processed with: die moulding at 25-30 second exposure and water spray hardening over the component. The hardening temperature was $830-840{ }^{\circ} \mathrm{C}$, the tempering was carried out for 6 hours at $430{ }^{\circ} \mathrm{C}$.

Sample workpiece 3 - home produced component, processed with: die moulding at 5-second exposure and the subsequent oil bath hardening. The hardening temperature was $830-840{ }^{\circ} \mathrm{C}$, the tempering was carried out for 6 hours at 430 ${ }^{\circ} \mathrm{C}$. 
Sample workpiece 4 - 65G steel check sample under conditions corresponding to delivery terms. The sample was not thermally processed.

Sample workpiece 5 - home produced component, processed with mineral oil hardening from the reheat temperature of $860^{\circ} \mathrm{C}$.

Sample workpiece 6 - home produced component, processed with: mineral oil hardening from the reheat temperature of $860{ }^{\circ} \mathrm{C}$, the air tempering was carried out for 4 hours at $420{ }^{\circ} \mathrm{C}$.

Sample workpiece 7 - home produced component that is in operation for the predetermined time.

The element composition analysis performed with the $\mathrm{x}$ ray fluorescent spectrometer (table 1) shows that all sample workpieces correspond to the $65 \mathrm{G}$ steel [4].

It is worth mentioning that sample workpieces 1 and 7 are similar in composition. It can be supposed that the steel for these sample workpieces has the same origin. However, the sample workpieces 1 and 7 have a higher manganese and chrome content compared to sample workpieces $2-4$. It should cause the increase in the hardening and throughhardening capacity degree, the amount of carbide precipitates and the heat-treated hardness. Chrome and silicon encourage the slowdown in the processes progressing during hardening and tempering, decrease the martensite start temperature $(\mathrm{Mn})$ and change the eutectoid carbon content (Cr) (Fig.1, 2).

TABLE I. RESULTS OF THE ELEMENT COMPOSITION ANALYSIS OF SAMPLE WORKPIECES PERFORMED WITH THE ARL9900 X-RAY FLUORESCENT SPECTROMETER (IF CARBON IS EXCLUDED), W. \%

\begin{tabular}{|c|c|c|c|}
\hline $\begin{array}{l}\text { Chemical } \\
\text { element }\end{array}$ & $\begin{array}{c}\text { Sample } \\
\text { workpiece } 1\end{array}$ & $\begin{array}{c}\text { Sample } \\
\text { workpiece } 2\end{array}$ & Sample workpiece 3 \\
\hline $\mathrm{Fe}$ & 97.58 & 96.94 & 97.48 \\
\hline $\mathrm{Mn}$ & 1.22 & 1.05 & 1.04 \\
\hline $\mathrm{Si}$ & 0.238 & 0.316 & 0.359 \\
\hline $\mathrm{Cr}$ & 0.165 & 0.0584 & 0.0869 \\
\hline $\mathrm{Ni}$ & 0.0337 & 0.0739 & 0.0815 \\
\hline $\mathrm{Cu}$ & 0.0060 & 0.122 & 0.0993 \\
\hline $\mathrm{P}$ & 0.0119 & 0.0080 & 0.0141 \\
\hline $\mathrm{S}$ & $\begin{array}{ll}\text { less } & \text { than } \\
0.001 & \end{array}$ & $\begin{array}{c}\text { less than } \\
0.001\end{array}$ & less than 0.001 \\
\hline $\begin{array}{l}\text { Chemical } \\
\text { element }\end{array}$ & $\begin{array}{c}\text { Sample } \\
\text { workpiece } 4\end{array}$ & $\begin{array}{c}\text { Sample } \\
\text { workpiece } 7\end{array}$ & $\begin{array}{c}\text { 65G steel } \\
(\text { GOST 14959-79) }\end{array}$ \\
\hline $\mathrm{Fe}$ & 97.60 & 97.39 & $\sim 97$ \\
\hline Mn & 1.03 & 1.21 & $0.90-1.20$ \\
\hline $\mathrm{Si}$ & 0.240 & 0.276 & $0.17-0.37$ \\
\hline $\mathrm{Cr}$ & 0.0735 & 0.169 & no more than 0.25 \\
\hline $\mathrm{Ni}$ & 0.141 & 0.0583 & no more than 0.25 \\
\hline $\mathrm{Cu}$ & 0.0948 & 0.0957 & no more than 0.20 \\
\hline S & $\begin{array}{ll}\text { less } & \text { than } \\
0.001 & \\
\end{array}$ & $\begin{array}{c}\text { less than } \\
0.001\end{array}$ & no more than 0.025 \\
\hline
\end{tabular}

The high concentration of manganese and chrome increases the temper brittleness. Therefore, higher requirements should be imposed on all stages of the steel thermal processing control.

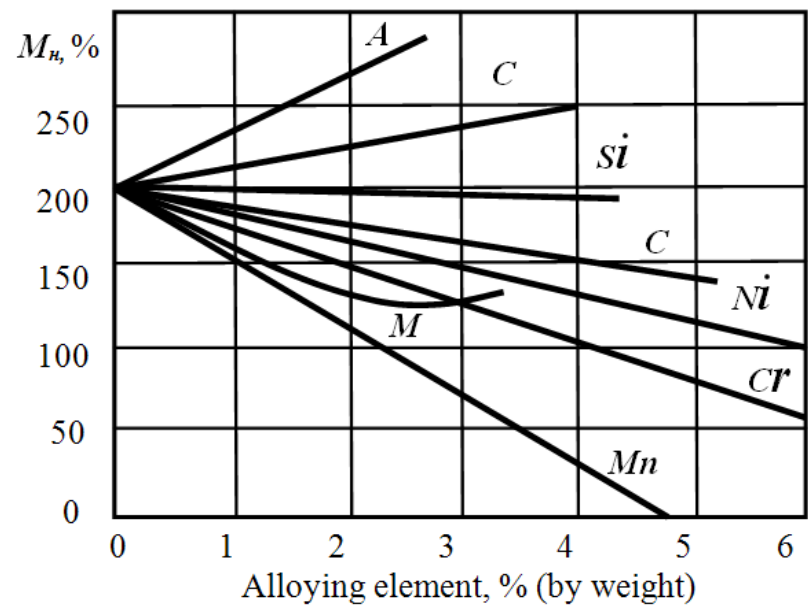

Fig. 1. Influence of alloy content on martensite start temperature $M n$ [5]

All sample workpieces were processed with metallographic analysis:

Sample workpiece 1. Sample workpiece 1 (Fig. 3) is a structure that is characteristic for carbon steel with increased manganese content (steels similar in composition to $65 \mathrm{G}$ steel) after hardening and a low-temperature tempering, i.e. a lower bainite.

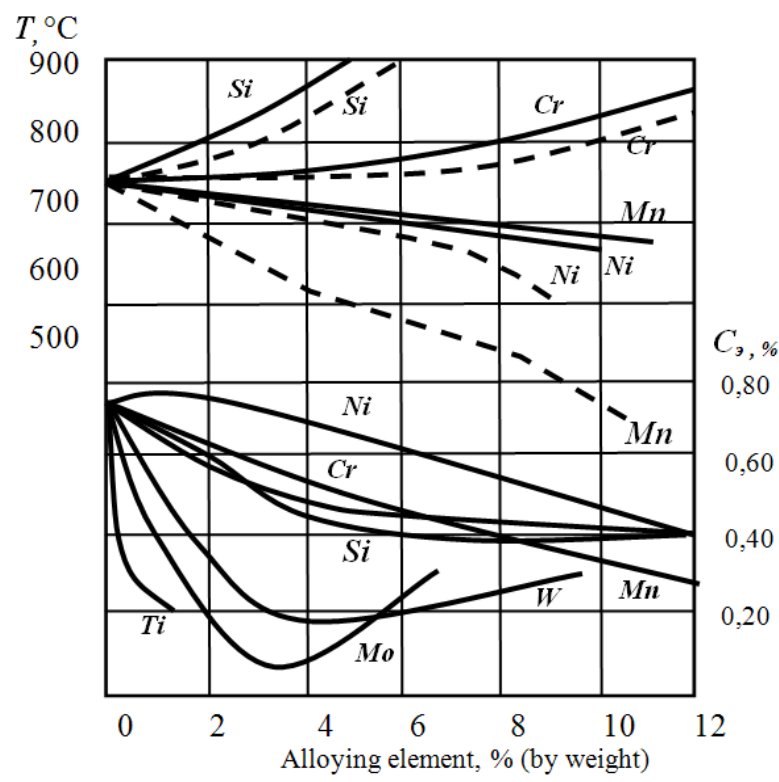

Fig. 2. Influence of alloy content on temperature position Ac1 and eutectoid change $S[6]$ : dashed lines correspond to the lower limits of the temperature value change 


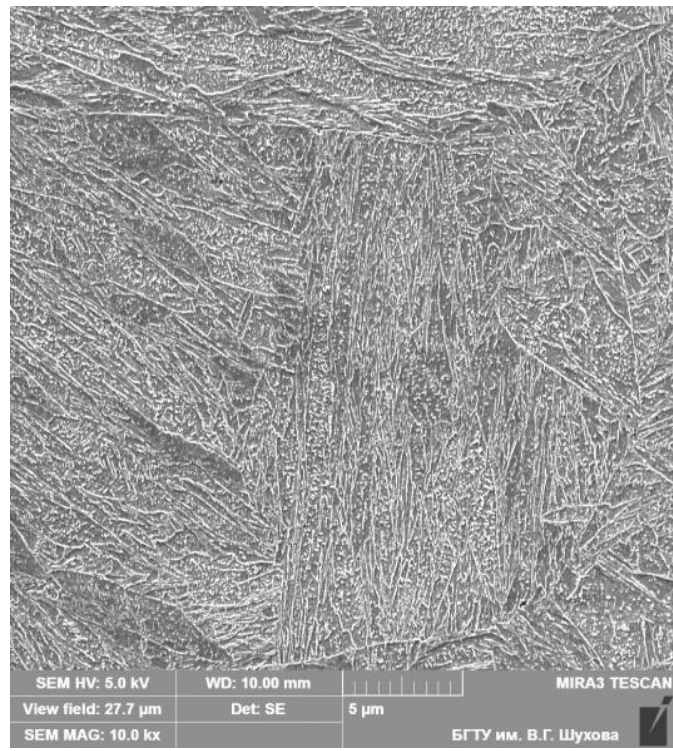

Fig. 3. Sample workpiece 1, electron microscopy, specimen, 2\%-nitric acid etching in spirit

The oil hardening was carried out from the temperature of $900{ }^{\circ} \mathrm{C}$. The small size carbide precipitation is explained by the slow carbon diffusion and supposes the tempering at 260$300^{\circ} \mathrm{C}, 30$-minute holding and water hardening.

According to Popov's formula [7] for this steel $\mathrm{Mn}=520-$ $320 \times(\% \mathrm{C})-45 \times(\% \mathrm{Mn})-30 \times(\% \mathrm{Cr})-20 \times(\% \mathrm{Ni}+\% \mathrm{Mo})-$ $5 \times(\% \mathrm{Si}+\% \mathrm{Cu})=520-320 \times 0,65-45 \times 1,2-30 \times 0,16=253$ ${ }^{\circ} \mathrm{C}$.

Thus, the thermal processing of sample workpiece 1 is similar to the thermal processing specified by regulations for HRC 50-55 hardness.

Sample workpiece 2. Sample workpiece 2 (Fig. 5) has a miscellaneous structure that consists of sorbitic pearlite crystallites and sorbitic pearlite zones or sorbate. This structure is typical for pieces that are slowly cooled down to the temperature of $650-730{ }^{\circ} \mathrm{C}$ followed by water chilling. Therefore, the martensite start temperature that is the principle transformation at hardening, is not used at thermal processing. The structure of sample workpiece 2 is obtained by an incomplete quenching mechanism [8] to form not the tempered structures of the hardening martensite but the sorbitic structures after the sample workpiece chilling, heated up to the subcritical temperature ("near hardening").

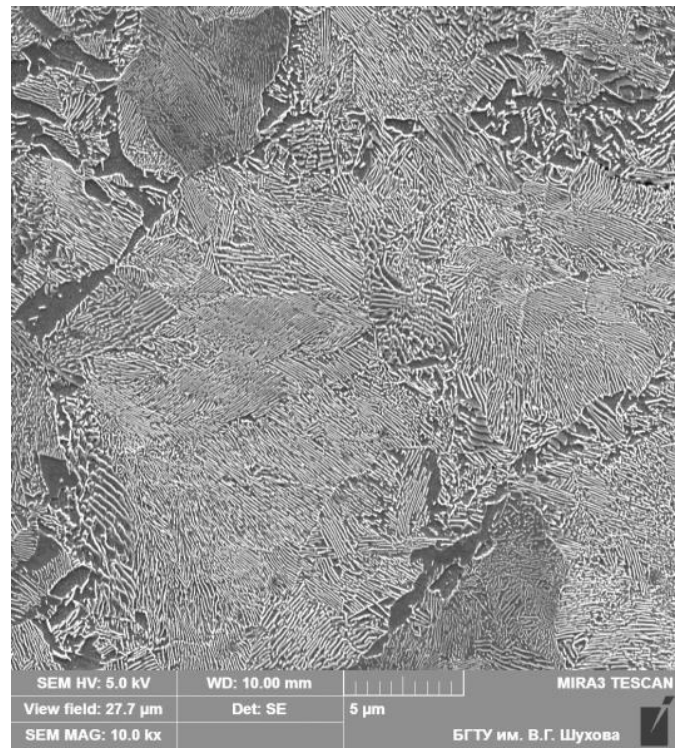

Fig. 4. Sample workpiece 2, electron microscopy, specimen, 2\%-nitric acid etching in spirit

Sample workpiece 3 . The sample workpiece 3 has a transition structure that consists of ferrite needles that are in incipience of ferrite grain and sorbate development. The piece experienced the thermal processing: hardening at the temperature that is above the critical thermal point Ac1 with the subsequent long-term high-temperature tempering. The high-temperature tempering caused the decomposition of the structure obtained after hardening (probably martensite bainitic) to form the ferrite needles and sorbate.

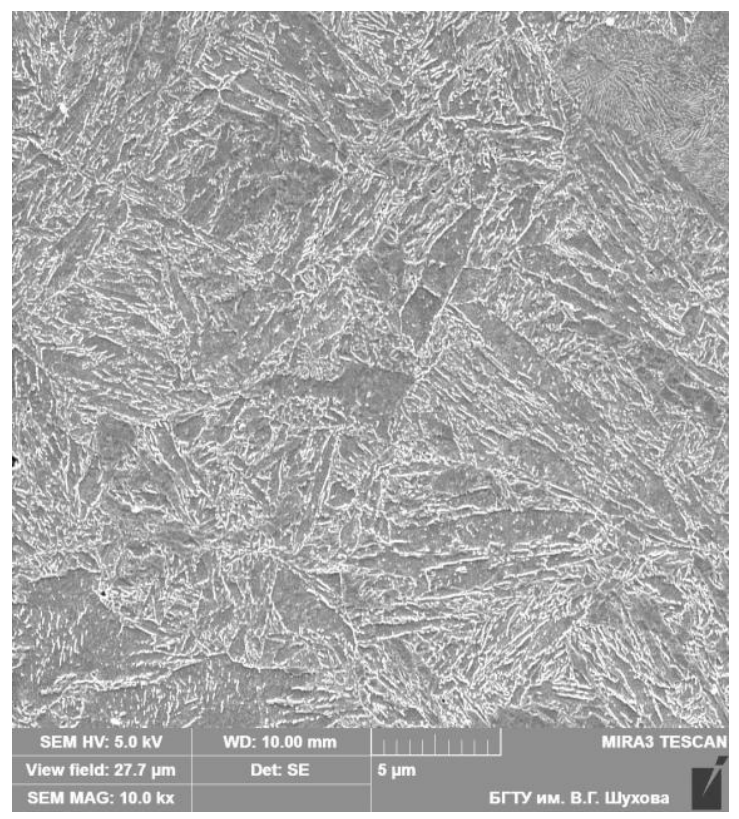

Fig. 5. Sample workpiece 3, electron microscopy, specimen, 2\%-nitric acid etching in spirit

Sample workpiece 4. The initial substance structure analysis (Fig. 7) shows that the structure is heterogeneous and consists of ferrite and granular pearlite grains. This structure is 
typical for rolled sheet and plate steel that is not air hardened $[9,10]$.

Sample workpiece 5. The structure of sample workpiece 5 (Fig.8) excludes the martensite start temperature and provides the austenite diffusion transformation processes into the lower bainite. The lower bainite structure is controlled by one or another attained cooling rate that is not controlled in this case under the terms of such thermal processing. During hardening, the structure of the sample workpiece 5 proves the necessity to take into account its size, the actual reheat temperature for hardening and the required hardening compound composition. The small-size sample workpiece is cooled down to a lower temperature when it is transported to the quenching bath. As a result of a lower initial temperature, the undercooled austenite lands at the level of bainite transformation instead of martensite start temperature.

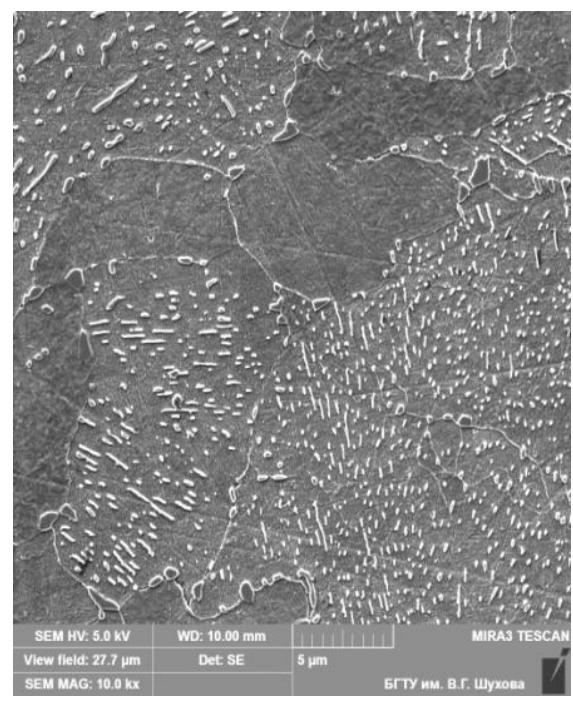

Fig. 6. Sample workpiece 4, electron microscopy, specimen, 2\%-nitric acid etching in spirit

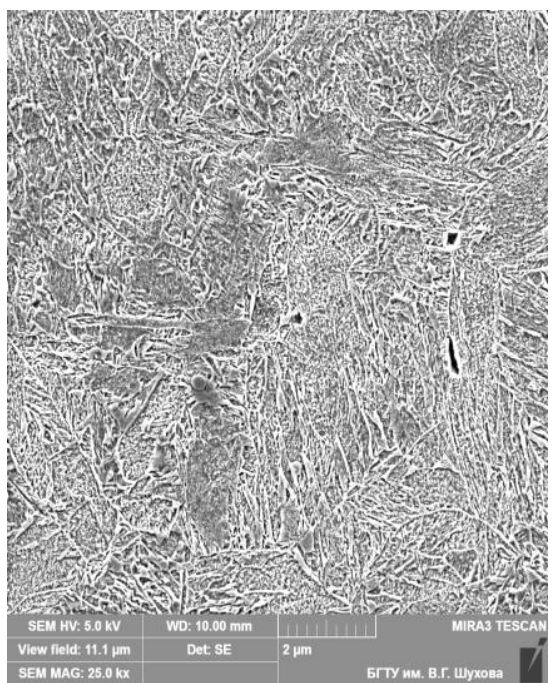

Fig. 7. Sample workpiece 5, electron microscopy, specimen, 2\%-nitric acid etching in spirit
Sample workpiece 6. Sample workpiece 6 is a sorbitic pearlite obtained by $65 \mathrm{G}$ steel tempering that has a structure shown in Fig.5.

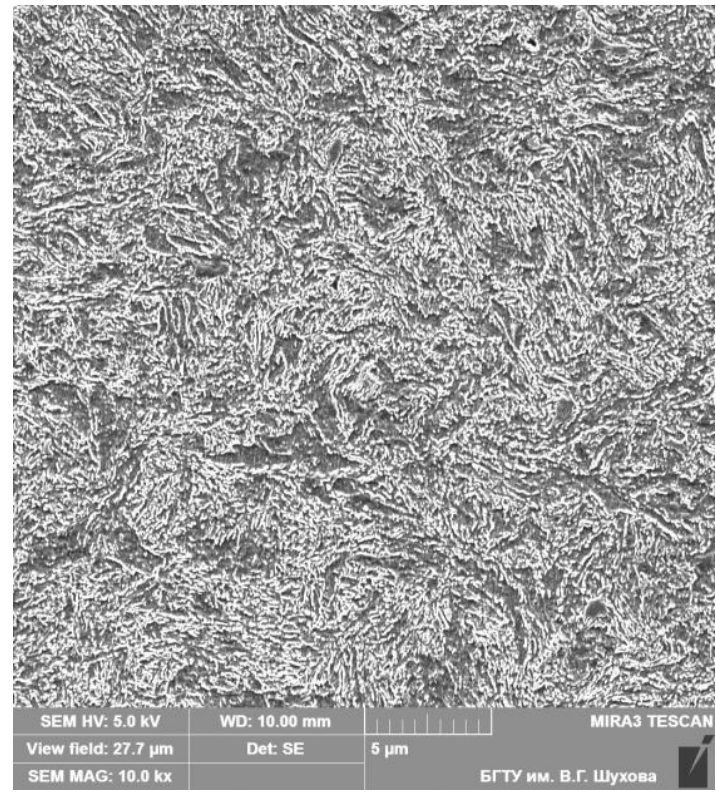

Fig. 8. Sample workpiece 6, electron microscopy, specimen, 2\%-nitric acid etching in spirit

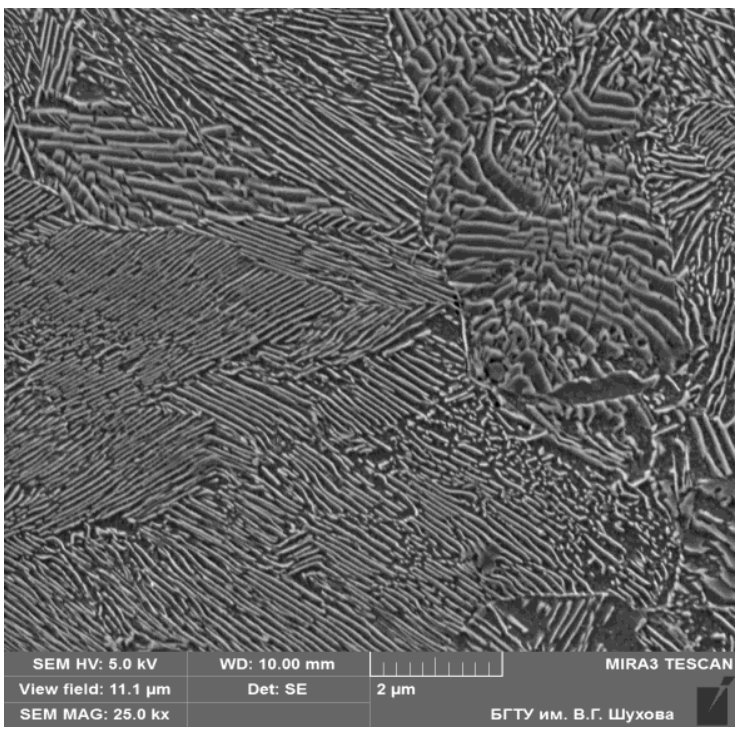

Fig. 9. Pieces of diverse structure transformation velocity, electron microscopy, specimen, 2\%-nitric acid etching in spirit

The thermal processing included the 4-hour steel tempering at $420{ }^{\circ} \mathrm{C}$. The structure pattern shows the holding time redundancy and an unreasonable high tempering temperature for the steel of this compound.

Moreover, at hardening the hold boundary of the partial basic transformation was found on one of the specimens (Fig. 10). The specimen is made of the sample workpiece that showed the lowest operational lifetime compared to the service life due to the severe wear. In figures, it can be seen that the metal base has a form of the lamellar sorbate structure. Moreover, scanning fixed the lamellar pearlite diffusion 
forming stage with other linear characteristics. This structure is typical for the piece that is slowly cooled down to the temperature of $650-730{ }^{\circ} \mathrm{C}$ followed by water or oil chilling. Therefore, the martensite start temperature that is the principle transformation during hardening, is not used at thermal processing. The sample workpiece structure in fig. 10 is obtained by an incomplete quenching mechanism to form not the tempered structures of the hardening martensite but the sorbitic structures after the sample workpiece chilling, heated up to the subcritical temperature ("near hardening")

Conclusion. The study results allowed the small enterprise to perfect the thermal processing:

1. The $65 \mathrm{G}$ steel reheat temperature at oil hardening must be about $900{ }^{\circ} \mathrm{C}$ to obtain the structure that provides high mechanical properties (elasticity).

2. Holding at hardening heat (austenitization) must be 5-10 minutes. Holding at hardening heat as well as the hardening heat encourage the carbide solution, cause an increase in martensite alloying (after hardening) and steel hardening.

3. It is necessary not to allow the high-scale decarburization, and as a consequence, the skin hardness loss.

4. The air tempering should be carried out at the temperature of $320-360{ }^{\circ} \mathrm{C}$ with the 30 -minute holding when the piece is heated up to the tempering temperature.

5. If the strength is not sufficient, it is necessary to increase the tempering temperature at a pitch of $30^{\circ} \mathrm{C}$ and to reduce the holding time by 5 minutes. When you choose the tempering temperature, it is possible to look to the obtained hardness in the heat-treater reference book.

6. After tempering, the piece should be cooled down quickly (in water) not to lose the impact hardness. Therefore, the higher the tempering temperature is, the higher the impact hardness is.

7. It is necessary to control thoroughly the thermal processing modes. Furnaces should be provided with thermocouples. The time between the piece removal from the furnace and its placement to the hardening compound is minimized. It is worth to stop using the disk moulding and hardening process concatenation.

8. 60S2G steel is recommended [4]. When this steel is thermally processed, it can be compared to the French steel by its properties.

9. To reduce the time because of the process concatenation, the breakdowns should be stacked (5-10 units) and reheated.

\section{SUMMARY}

1. The given results of the study of the $65 \mathrm{G}$ steel structure show the possibility of a more profound physicometallurgical study of metals and alloys.

2. The sample scanning allows one to study the influence of diverse thermal processing modes at runtime and to get more informative photos compared to the standard methods to study the steel and alloy microstructure.

3. The nanometer-scale study allows fixing the nonequilibrium diffusion processes of decay and phase and structure forming due to the heat gradient in the small area of the test piece.

4. Sample workpiece 1 produced in France corresponds to the thermal processing that provides the structure of the lower bainite. The lower bainite provides high mechanical properties and wear-resistance as specified in performance standards.

5. To increase the piece wear resistance that leaves behind the best test units of similar products, it is necessary to use the diamond-like nanostructured coating $[11,12,13]$.

6. The application of the diamond-like coating should be carried out at the temperature that is not higher than $100^{\circ} \mathrm{C}$ in vacuum by a momentum electric-arc method.

7. The existing process of the component thermal processing should be changed.

\section{Acknowledgment}

The work was carried out in the framework of the Program of flagship university development on the basis of Belgorod State Technological University named after V.G. Shoukhov, using equipment of High Technology Center at BSTU named after V.G. Shoukhov.

\section{References}

[1] D. Sarid, "Exploring scanning probe microscopy with "Mathematica," John Wiley\& Sons, Inc., New York, 1997, p. 262.

[2] New TESCAN instrument / www.tescan. com / en-us/

[3] A.A. Afanasiev, "Increase in surface quality of machine components", Belgorod: Publishing house of BSTU named after V.G. Shoukhov, 2007, p. 235.

[4] Yu.G. Dragunov, A.S. Zubchenko, Yu.V. Kashirsky, "Grade guide of steels and alloys," Moscow, 2014, p. 1216.

[5] V.T. Batienkov, G.G. Seferov, A.L. Fomenko, "Material science", Moscow: INFA-M, 2014, p. 151

[6] B.N. Arzamasov, V.N. Makarova, G.G. Mukhin, V.I. Silaeva, N.M Ryzhov, "Material science," Moscow: MSTU names after E.N. Baumana. 2008, p. 655

[7] V.S. Biront, "Theory of metal thermal processing. Thermophisical fundamentals and calculations," Krasnoyarsk, 2001, p. 132.

[8] Yu.F. Bashnin, B.K. Ushakov, A.G. Sekey, "Steel thermal processing technology," Moscow: Metallurgy, 1986, p. 424.

[9] Yu.M. Lakhtin, "Metal science and metal thermal processing", Moscow: Metallurgy, 1993, p. 448.

[10] Yu.P. Soltsev, E.I. Pryakhin, "Material science," Saint-Peterburg: Khimizdat, 2007, p. 784

[11] A.A. Rempel, "Nanotechnologies, properties and application of nanostructered materialls," Chemistry successes, 2007, vol. 76(5), pp. 476-500.

[12] Method to form an extrahard amorphous carbon coating in vacuum (Patent \# 2430986).

[13] A.A. Afanasiev, K.S.Ivleva, D.S. Prokhorenkov, "Nanometrology in technical studies," IrSTU Bulletin, 3(98), pp. 26-33, 2015 